\title{
A Study on Rotary Weeding Blade Installation Angle for Reduction of Hand Vibration in Working Type Cultivator
}

\author{
Tae Hyeong Kwon ${ }^{1}$, Joonyong Kim ${ }^{1}$, Chungu Lee ${ }^{1}$, Tae Gyoung Kang ${ }^{3}$, Byeong-Mo Lee ${ }^{4}$ Joong-Yong Rhee ${ }^{1,2 *}$ \\ ${ }^{1}$ Dept. of Biosystems Engineering, Seoul National University, Seoul, 151-921, Republic of Korea \\ ${ }^{2}$ Research Institute for Agriculture and Life Sciences, Seoul National University, Seoul, 151-921, Republic of Korea \\ ${ }^{3}$ Dept. of Agricultural Engineering, National Academy of Agricultural Science, \\ Rural Development Administration. Suwon, Korea \\ ${ }^{4}$ Dept. Of Organic Agriculture, National Academy of Agricultural Science, Rural Development Administration, \\ Suwon, Gyeonggi, 441-707, Republic of Korea
}

Received: November $20^{\text {th }}, 2013$; Revised: February $10^{\text {th }}, 2014 ;$ Accepted: February $19^{\text {th }}, 2014$

\section{Abstract}

Purpose: Walking type cultivator used for weeding generated excessive handle vibration as well as bouncing motion depending on the weeding speed. This research was conducted to define a design factor of the rotary weeding blades for reducing soil reaction forces as well as hand vibration. Methods: The motion and forces acting on the rotary blades were reviewed to find out the most influencing parameter on hand vibration. The installation angle (IA) of the blade was selected and analyzed to determine the condition of no reaction force less. For removing the unnecessary upward soil reaction, the design factor theory of weeding blade was suggested based on geometrics and dynamics. For evaluation of design factor theory, the experiment in situ was performed base on ISO 5349:1. The vibration $a_{\mathrm{hv}}$ and theoretical value $\mathrm{X}_{\mathrm{MF}}$ were compared with two groups that one was positive group $\left(X_{M F}>0\right)$ and the other was negative group $\left(X_{M F}<0\right)$. Results: $X_{M F}$ was derived from rotational velocity, forward velocity, disk diameter, weeding depth, blade's width and IA of blade. Two groups had significant difference $(\mathrm{p}<0.05)$. In aspect of the group mean total exposure duration, positive group was $17.53 \%$ bigger than negative group. When disk radius 100, 150 and $200 \mathrm{~mm}$, minimum IAs were $4 \sim 27^{\circ}, 3 \sim 15^{\circ}$ and $2 \sim 10^{\circ}$, respectively. A spread sheet program which calculated $\mathrm{X}_{\mathrm{MF}}$ was developed by Excel 2013. Conclusions: According to this result, minimum IA of weeding blade for soil reaction reduction could be obtained. For reduction hand-arm vibration and power consumption, minimum IA is needed.

Keywords: Hand-arm Vibration, ISO 5349, Rotary Weeding Cultivator, Walking Cultivator, Weeding Blade

\section{Introduction}

Organic farm receive attention from consumers because of its food safety. $72.8 \%$ of consumers usually checked organic agricultural products certification mark when they purchased it (Jeong and Jang, 2012). The price of organic agricultural products was higher than prevalent agricultural product by $145 \sim 271 \%$ (Yoo, 2012) and cultivation area of organic farm increased from 5,000 ha

\footnotetext{
*Comesponding author: Joong-Yong Rhee

Tel: +82-2-880-4605; Fax: +82-2-885-8027

E-mail: jyr@snu.ac.kr
}

in 2001 to 170,000 ha in 2011. These facts indicate that organic agricultural products offer a high income to farmers and organic farm market will be increased that was mentioned by Kim et al. (2012). However, there is weed problem which disturb growth of crops in organic farming. Therefore, weed control has been an important issue in organic farming.

Weeding cultivator can provide eliminating weeds with saving labor time. Walking type cultivator could be used in upland field because of its small size. However, a worker is exposed to hand-arm vibration transmitted by working type cultivator unlike riding type weeder. 
International Organization for Standardization (ISO) offers a standard for measurement and evaluation of human exposure to hand-transmitted vibration (ISO, 2001). According to ISO 5349, excessive exposure to hand-transmitted vibration can induce disturbances in finger blood flow and it brings complex of peripheral vascular, neurological and musculoskeletal disorder, so called 'hand-arm vibration syndrome (HAVS)'.

The Korea Occupational Safety and Health Agency (KOSHA) also offers a guideline for measurement and evaluation of vibration based on 'Mechanical vibration Measurement and evaluation for human exposure to hand-transmitted vibration' of ISO, 'Guide for the measurement and evaluation of human exposure to vibration transmitted to the hand' of American national standard and 'Threshold limit values for chemical substances and physical agents \& biological exposure indices, Hand-arm (segmental) vibration' of American conference of Government Industrial Hygienists (ACGIH) (KOSHA, 2012). This guideline was created by a legal basis about industrial safety, it means that vibration is increasingly important in evaluation factors of machinery. In this trends, many researches in industrial area were performed for evaluation harmful vibration (Kim and Paik, 1996; Kim et al., 2012; Park and Huh, 2004).

In agricultural machinery, walking type cultivator transmits enormous vibration as contrasted with the other agricultural machineries (Noh and Park, 2009). There are two vibration source in walking type cultivator. One is an engine of cultivator was vibration source and the other is working part (Park et al., 2004). In the case of vibration from engine, an isolating device reduced $27 \%$ of handle vibration (Park and Kim, 2002). However working parts consisted of rotary disk and weeding blades produce low frequency, it is more harmful operator's health (Yim et al., 2002). Therefore, research for vibration from working part is needed.

While walking type cultivator is working, soil reaction is occurred. Weeding blade receive force from soil like shear stress and fraction generated by soil cutting and compaction. However, unnecessary upward reaction is occurred by virgin soil compaction of weeding blade depended on forward velocity of cultivator, rotational velocity of disk and shape of weeding blade. Beeny and Khoo (1970) already mentioned about shape of weeding blade.

This study was conducted to suggest a design parameter which affected on the soil reaction forces which was acting on the surface of rotary weeding blade, to prove the effect of the design parameter by measuring the hand vibration. Ultimate goal of this paper is to develop a handy working type rotary cultivator for female and old age in organic farms. Based on the theoretical investigation, an index which determines occurrence of unnecessary soil reaction on the rotary blade was developed. The effect of the design parameter was experimentally proved in the field test. Based on theoretical investigation and the field test, the proper installation angle (IA) of weeding blade for working type cultivator was suggested and a simple calculation spread sheet was developed.

\section{Materials and Methods}

\section{Design parameters of the rotary weeding blade}

Rotary blades for cultivation could be classified into L-shaped blade, C-shaped blade and so on. The weeding blades are basically same as the cultivating blades in structure and power transmission but its cultivation

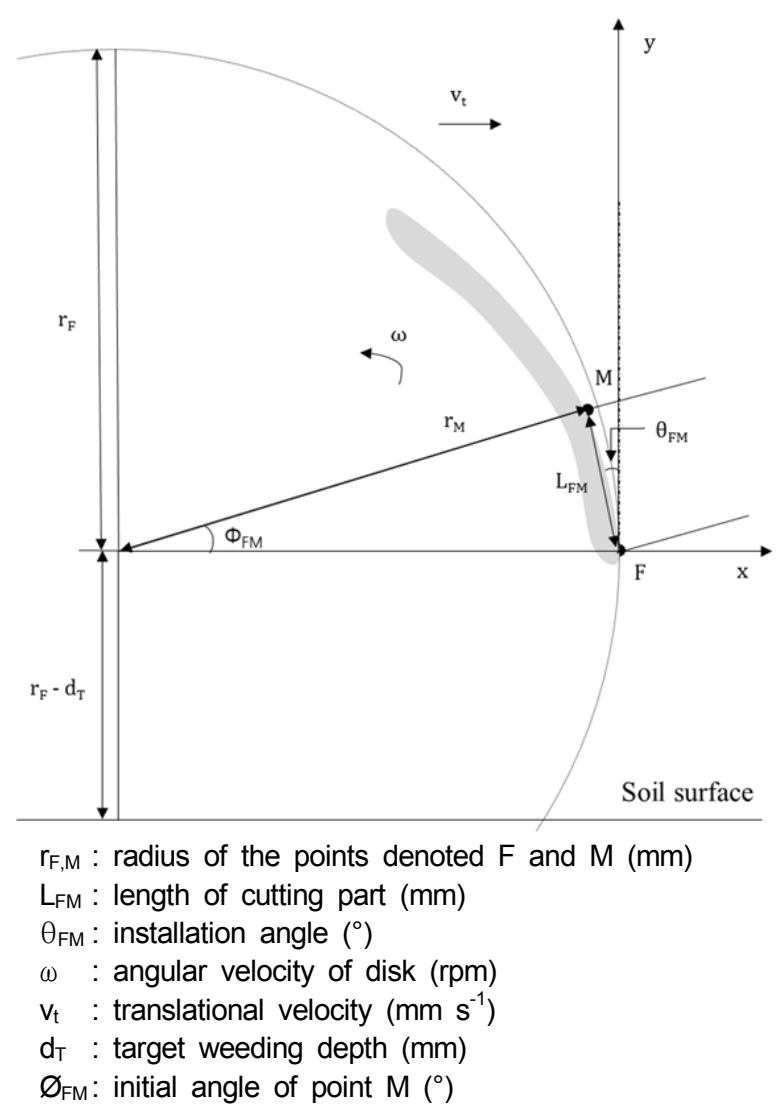

Figure 1. Design parameter and dynamic parameters on the rotary blade. 
depth is shallow (from $10 \sim 30 \mathrm{~mm}$ ). Dedicated rotary weeding machine equipped several rotary disks on a horizontal axis on which light weighted blades are fixed on the outer edge of the disk. The blade could be straight or curved. Figure 1 shows the dynamic parameters and the design parameter of the rotary blade. The dynamic parameters are working velocity and rotational speed of the rotary disk and the design parameters are radius of rotary disk, length, thickness and width of the blades as well as the IA of the blade.

Tip of the rotary blade showed rotational and translational motion and make a trochoid curve. X-coordinate of a point which moves along the trochoid curve is expressed like below.

$$
x(t)=R \cos \omega t+v_{t} t
$$

where, $x(t)$ : $\mathrm{x}$-coordinate of point

$$
\begin{array}{ll}
R & : \text { rotation diameter } \\
\omega & : \text { rotational velocity } \\
v_{t} & : \text { translational velocity } \\
t & : \text { time }
\end{array}
$$

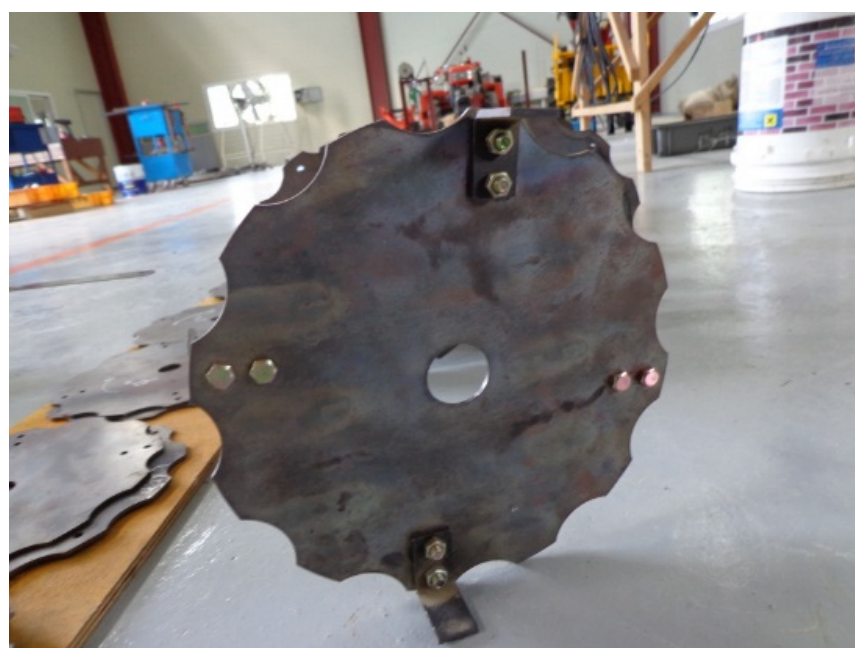

\section{Materials for evaluation of weeding blade}

\section{Weeding blade and walking type cultivator}

According to equation (3), three kinds of weeding blade were fabricated. Disk diameter was $145 \mathrm{~mm}$, width of blade was $10 \mathrm{~mm}$. The IAs of blades were $0,4,8^{\circ}$. Four weeding blades were attached on a disk. The appearance of weeding blade is shown below (Figure 2).

In this study, developed weeding blades were attached on agricultural weeding machinery, KT-400 (Kawashima, Japan). The engine of KT-400 were TB43 (Mitsubishi, Japan) that was single cylinder 2-cycle engine. Specification included the engine is shown Table 1.

Four disks were assembled in this machinery. Weeding width was fixed by $300 \mathrm{~mm}$. Disk could be separated from the cultivator using a pin. Attached appearance is shown Figure 3.

\section{Experimental design}

Rice paddy in University Farm, College of Agriculture \& Life Science, Seoul National University, Suwon-si, Gyeonggi-do was selected for experimental field. There were some stubbles in the rice paddy because harvesting had been

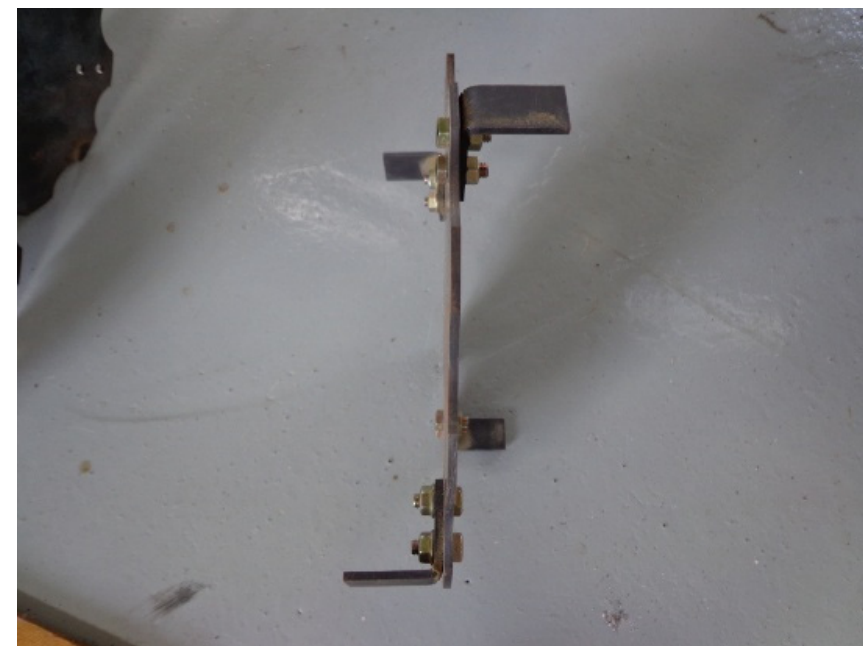

Figure 2. Rotary disk and weeding blade assembly, side view (right) and front view (left).

Table 1. Specification of KT-400 weeding cultivator

\begin{tabular}{cc} 
Parameter & Content \\
\hline Model & Kawashima KT-400 \\
\hline $\mathrm{L} \times \mathrm{W} \times \mathrm{H}$ & $100 \times 47 \times 97 \mathrm{~cm}$ \\
\hline Weight & $10.3 \mathrm{~kg}$ \\
\hline \multirow{2}{*}{ Engine } & Mitsubishi TB43 $(1.25 \mathrm{~kW}), 9,000 \mathrm{rpm}$ \\
& Air-cooled, 2-cycle, gasoline engine \\
& 42.7 cc of displacement \\
\hline
\end{tabular}


complete (Figure 4). Test was performed next to the stubbles for reducing error.

Soil compaction of the experimental field was 954.6 $\mathrm{kPa}$ measured by soil compaction meter (Spectrum Technologies Inc., USA). The soil compaction was acquired from average of 5 spots on the experimental field. Soil texture was silt loam analyzed by request to National Instrumentation Center for Environmental Management, Seoul National University, Seoul and result of analysis is shown Table 2.

The experiment was executed with three kinds of blade IAs $(0,4,8)$, three kinds of forward velocity (slow, medium, fast) and three repetition. It is difficult to make
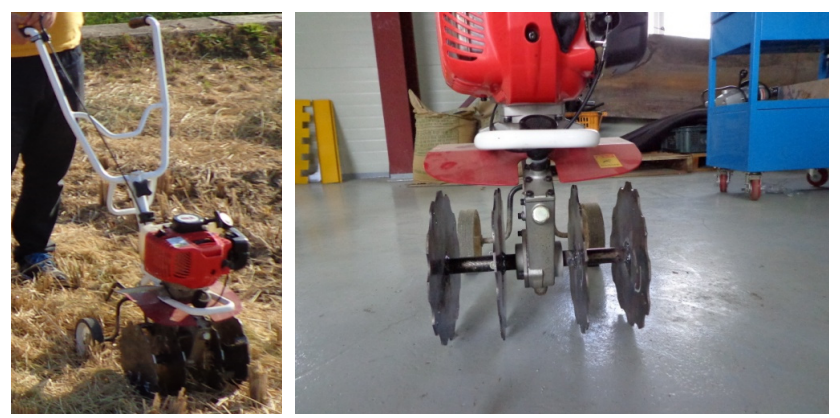

Figure 3. View of test weeding cultivator.

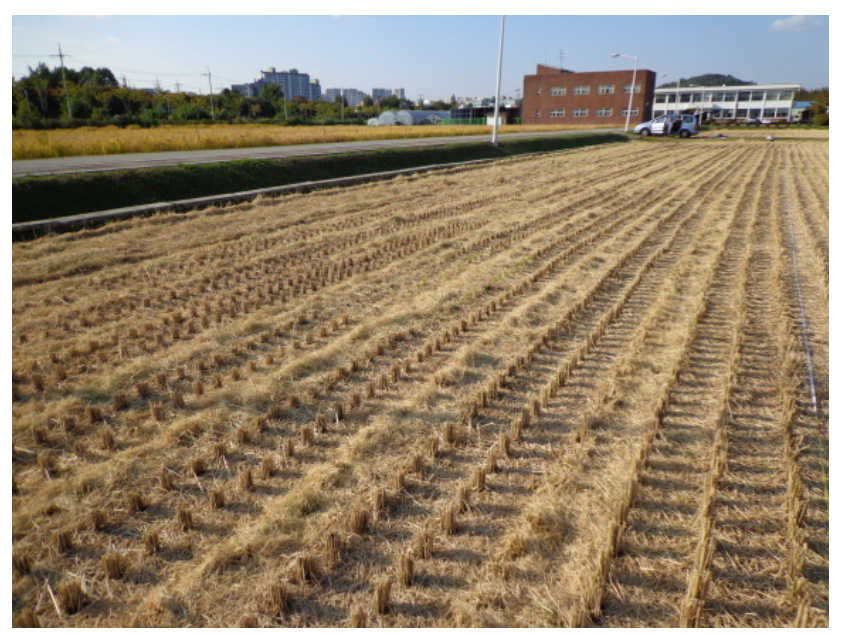

Figure 4. Test site for hand vibration measurement.

Table 2. Soil texture of test site for hand vibration measurement

\begin{tabular}{|c|c|c|c|c|}
\hline Sample No. & Sand (\%) & Silt (\%) & Clay (\%) & Soil Texture \\
\hline 1 & 27.06 & 67.49 & 5.45 & Silt Loam \\
\hline 2 & 23.25 & 71.32 & 5.43 & Silt Loam \\
\hline 3 & 36.92 & 59.18 & 3.90 & Silt Loam \\
\hline 4 & 22.68 & 72.32 & 5.00 & Silt Loam \\
\hline 5 & 33.30 & 62.22 & 4.48 & Silt Loam \\
\hline
\end{tabular}

the forward velocities equal in each test, so forward velocities were classified by rough categories. The other factors were assumed same on each test because it were made similar deliberately. Weeding depth was about 10 $\mathrm{mm}$, rotational velocity of disk was about $350 \mathrm{rpm}$. Translational velocity was calculated with distance (15 $\mathrm{m}$ ) and driving time measured by prevalent ruler and stopwatch.

\section{Devices for measurement}

Transducer is needed for measuring vibration. Tri-axial accelerometer, 3273A1T (Dytran Instruments Inc., USA) was used for transducer (Figure 5). The accelerometer transmits analog signal $10.35 \mathrm{mV} / \mathrm{g}$ on x-axis, $9.94 \mathrm{mV} / \mathrm{g}$ on $\mathrm{y}$-axis and $10.25 \mathrm{mV} / \mathrm{g}$ on $\mathrm{z}$ axis

Analog signal input module, NI 9234 (National Instruments, USA) was used for data acquisition (Figure 6). The module receives analog signals from the transducer and transmits digital signals to Note PC with a chassis (NI cDAQ-9178). The specification of NI 9234 is shown Table 3.

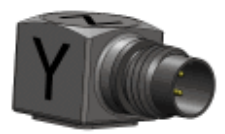

Figure 5. Tri-axial accelerometer, 3273A1T (Dytran, 2013).

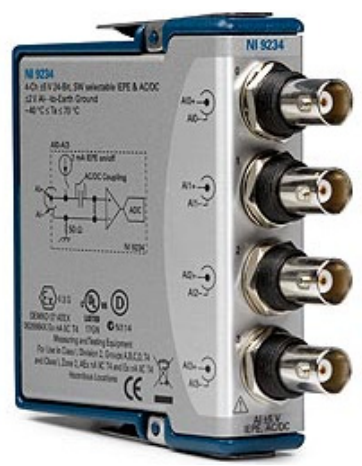

Figure 6. NI 9234 data acquisition module (NI, 2013).

Table 3. Specifications of data acquisition module for hand vibration measurement (NI, 2013)

\begin{tabular}{|cc|}
\hline Parameter & Content \\
\hline Model & NI 9234 Compact DAQ \\
\hline Channel & 4 \\
\hline Resolution & $24 \mathrm{bit}$ \\
\hline Sample rate & $51.2 \mathrm{kS} / \mathrm{s}$ \\
\hline Analog input range & $-5 \sim 5 \mathrm{~V}$ \\
\hline Measurement type & Accelerometer, Microphone \\
\hline
\end{tabular}


Measurement program was developed by LabVIEW 2009 (National Instruments, USA) (Figure 7). The program receives digital signal from data acquisition module by 10 $\mathrm{kHz}$ and displays time-domain on left chart. This program converts time-domain data to frequency-domain by Fast Fourier Transform (FFT) with root mean square (r.m.s.) value. After FFT, frequency-domain data is shown right chart.

\section{Measurement and data processing method based on ISO 5349:1}

ISO 5349:1 offers measurement and data processing method. This section was written based on ISO 5349:1. The cultivator had handle, so coordinate for the hand position was selected "Handgrip". The accelerometer was attached based on Figure 8.

For evaluation, the spectrum of acceleration data is needed data processing. First, spectrums of each test was acquired by averaging depending on frequency data in 20 sec. Second, continuous spectrum of $6.3 \sim 1,250 \mathrm{~Hz}$ is needed to separating by center frequency of a one-thirdoctave band. Third, one-third-octave band data converts to frequency-weighted acceleration like equation (2) offered ISO 5349:1. The weighting factor offered by same standard is shown Table 4.

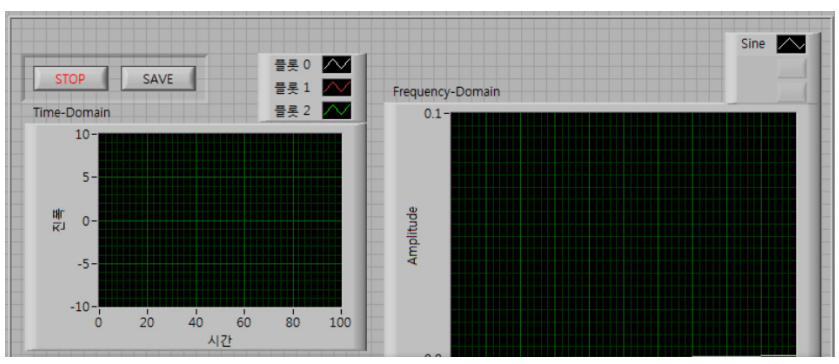

Figure 7. Measurement program based on LabVIEW 2009.
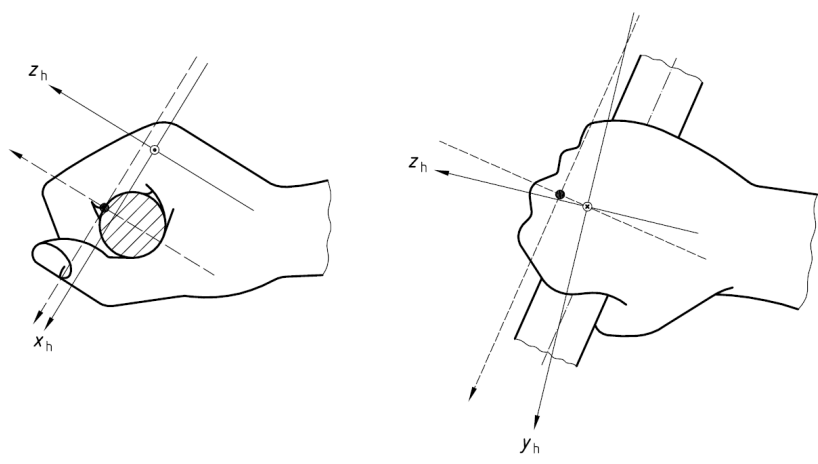

Figure 8. Coordinate system of "Handgrip" position offered (ISO, 2001).

$$
a_{h w}=\sqrt{\sum_{i}\left(W_{h i} a_{h i}\right)^{2}}
$$

where, $W_{h i}$ : the weighting factor for the $i$ th onethird-octave band

$a_{h i}$ : the r.m.s. acceleration measured in the $i$ th one-third-octave band $\left(\mathrm{m} \mathrm{s}^{-2}\right)$

Table 4. Frequency weighting factors $W_{\text {hi }}$ for hand-transmitted vibration with band limiting ${ }^{\text {a) }}$ for conversion of one-third-octave band magnitudes to frequency-weighted magnitudes. This table is cited ISO $5349: 1$

\begin{tabular}{|c|c|c|}
\hline $\begin{array}{c}\text { Frequency band } \\
\text { number }{ }^{\text {b) }} i\end{array}$ & $\begin{array}{l}\text { Nominal mid } \\
\text { frequency } \mathrm{Hz}\end{array}$ & $\begin{array}{c}\text { Weighting factor } \\
W_{\mathrm{hi}}\end{array}$ \\
\hline 6 & 4 & 0.375 \\
\hline 7 & 5 & 0.545 \\
\hline 8 & 6.3 & 0.727 \\
\hline 9 & 8 & 0.873 \\
\hline 10 & 10 & 0.951 \\
\hline 11 & 12.5 & 0.958 \\
\hline 12 & 16 & 0.896 \\
\hline 13 & 20 & 0.782 \\
\hline 14 & 25 & 0.647 \\
\hline 15 & 31.5 & 0.519 \\
\hline 16 & 40 & 0.411 \\
\hline 17 & 50 & 0.324 \\
\hline 18 & 63 & 0.256 \\
\hline 19 & 80 & 0.202 \\
\hline 20 & 100 & 0.160 \\
\hline 21 & 125 & 0.127 \\
\hline 22 & 160 & 0.101 \\
\hline 23 & 200 & 0.0799 \\
\hline 24 & 250 & 0.0634 \\
\hline 25 & 315 & 0.0503 \\
\hline 26 & 400 & 0.0398 \\
\hline 27 & 500 & 0.0314 \\
\hline 28 & 630 & 0.0245 \\
\hline 29 & 800 & 0.0186 \\
\hline 30 & 1,000 & 0.0135 \\
\hline 31 & 1,250 & 0.00894 \\
\hline 32 & 1,600 & 0.00536 \\
\hline 33 & 2,000 & 0.00295 \\
\hline
\end{tabular}


$a_{\text {hv }}$ calculated by equation (3) is the vibration total value of frequency-weighted r.m.s. acceleration for the three measured axis.

$$
a_{h v}=\sqrt{a_{h w, x}^{2}+a_{h w, y}^{2}+a_{h w, y}^{2}}
$$

where, $a_{h v}$ : vibration total value of frequency-weighted r.m.s. acceleration $\left(\mathrm{m} \mathrm{s}^{-2}\right)$

$$
a_{h w, x}, a_{h w, y}, a_{h w, z} \text { : values of } a_{h w} \text { for the axis }
$$
denoted $x, y$ and $z$ respectively.

The daily vibration exposure, $A(8)$ is calculated with frequency-weighted acceleration by equation (4).

$$
A(8)=a_{h v} \sqrt{\frac{T}{T_{0}}}
$$

where, $A(8)$ : the daily vibration exposure $\left(\mathrm{m} \mathrm{s}^{-2}\right)$

$$
\begin{gathered}
a_{h v} \quad: \text { vibration total value of frequency- } \\
\text { weighted r.m.s. acceleration }\left(\mathrm{m} \mathrm{s}^{-2}\right) \\
T \quad: \text { the total daily duration of exposure to } \\
\text { the vibration } a_{h v} \\
T_{0} \quad \text { : the reference duration of } 8 \mathrm{~h}(28,800 \mathrm{sec})
\end{gathered}
$$

The group mean total (lifetime) exposure duration, equation (5) is estimated to produce finger blanching in $10 \%$ of exposed person.

$$
D_{y}=31.8(A(8))^{1.06}
$$

where, $A(8)$ : the daily vibration exposure $\left(\mathrm{m} \mathrm{s}^{-2}\right)$

$D_{y} \quad$ : the group mean total (lifetime) exposure duration (year)

\section{Data analyze method}

For verification of design factor theory, an index which determines occurrence of unnecessary soil reaction on the rotary blade and $a_{\mathrm{hv}}$ were compared. Weeding depth, disk diameter, blade width and rotational velocity were assumed constant. The IA of blade was three kinds and it was used variables. Forward velocity had been three kinds, however, it was different in every test actually. Therefore, calculated index and $a_{\mathrm{hv}}$ were acquired and cross-correlated. R 3.0.1 (R core Team, 2013) was used for statistical analysis, T-test.

\section{Results and Discussion}

\section{Design factor theory of weeding blade}

Design factor of rotary weeding blade for reducing soil reaction and hand vibration was delineated by method of geometrical and dynamic. For analysis, two actual points on a curved type weeding blade were created. One (F) was the edge of the blade, the other (M) was another point on the blade. The positions of these points were different based on the IA of the blade. The unnecessary soil reaction is occurred when trace of $\mathrm{M}$ pull ahead of $\mathrm{F}$ trace because soil compaction occurs (Figure 9). Therefore, $X_{\mathrm{MF}}$ between $\mathrm{X}$-axis coordinate of $\mathrm{A}$ and $\mathrm{B}$ on a soil surface can be index that unnecessary soil reaction is occurred or not.

$\mathrm{F}$ and $\mathrm{M}$ have different disk diameter because of the IA among blade points. Time of reaching to soil surface is different each other because of initial position. The other factors of point $\mathrm{F}$ and $\mathrm{M}$ like rotational velocity and translational velocity are same. Time of reaching to soil surface can be obtained based on rotational angle like below.

$$
\begin{aligned}
t_{F} & =\left(\frac{\pi}{2}-\arccos \frac{d_{r}-r_{F}}{r_{F}}\right) \omega^{-1} \\
t_{B} & =\left(\frac{\pi}{2}-\arccos \frac{d_{T}-r_{F}}{r_{M}}-\varphi\right) \omega^{-1}
\end{aligned}
$$

where, $t_{F}$ : time when point $\mathrm{F}$ reach soil surface $(\mathrm{s})$

$t_{M}$ : time when point $M$ reach soil surface $(\mathrm{s})$

The other variables are shown Figure 1.

According to this analysis, $\mathrm{X}_{\mathrm{MF}}$ can be expressed below. The lower rotational velocity, the higher translational

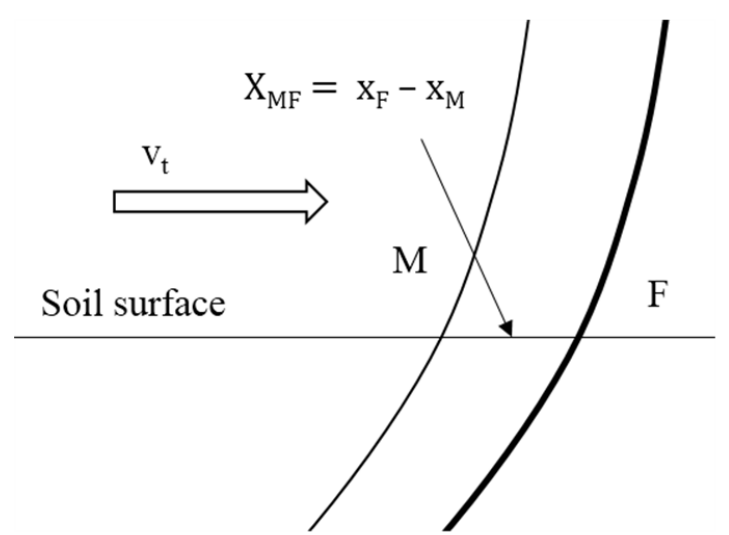

Figure 9. Trace of two points $\mathrm{F}$ and $\mathrm{M}$ on a blade. $\left(\mathrm{X}_{\mathrm{MF}}\right.$ : Trace gap between $\mathrm{F}$ and $\mathrm{M}$ on soil surface). 
velocity and the smaller the IA makes $\mathrm{X}_{\mathrm{MF}}$ smaller.

$$
X_{M F}=r_{F} \cos \left(\omega t_{F}\right)+v_{t} t_{F}-r_{M} \cos \left(\omega\left(t_{M}+\frac{\varnothing_{F M}}{\omega}\right)\right)+v_{t} t_{B}(7)
$$

where, $X_{M F}$ : index ( interval between A and B on a soil surface ( $\mathrm{mm})$ )

The other variables are shown Figure 1 and equation (6).

\section{Vibration characteristic of the cultivator}

The data was divided by two groups that one was positive group ( $\mathrm{PG}, \mathrm{X}_{\mathrm{MF}}>0$ ), the other was negative group $\left(N G, X_{M F}<0\right)$. Vibration spectrums of $P G$ and $N G$ are shown Figure 10. The acceleration of $\mathrm{x}$-axis was not described because of its low value. Upward vibration, $\mathrm{z}$-axis and $\mathrm{y}$-axis that means pitch axis were higher than $\mathrm{x}$-axis. The $\mathrm{x}$-axis was collinear axial through a part of chassis which received vibration and transmitted it to handle. The frequency was higher, the vibration was lower. The study of Park and Kim (2002) and Noh and Park (2009) showed same result.

\section{Calculation of $\mathrm{X}_{\mathrm{MF}}$ with six factor}

Three kinds of forward velocity were considered. Driving time of "high" forward velocity was from 16.1 to $22.4 \mathrm{sec}$, "medium" forward velocity was from 24.4 to

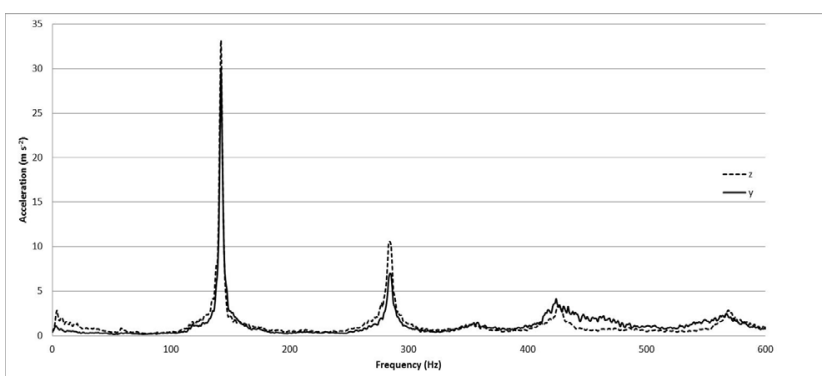

(a) Negative group $\left(X_{M F}<0\right)$

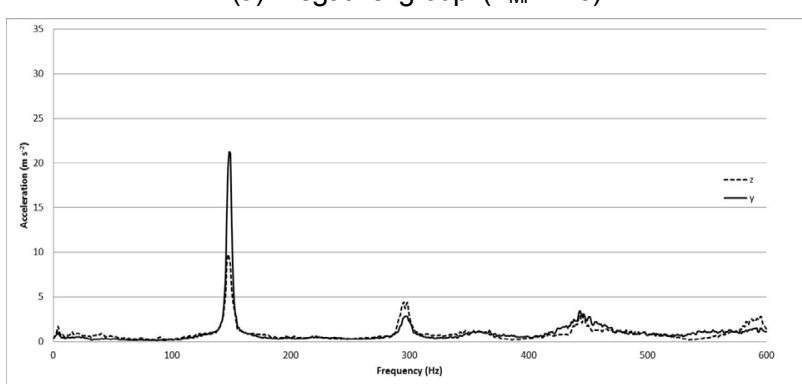

(b) Positive group $\left(X_{M F}>0\right)$

Figure 10. Hand vibration spectrums in the $y$ and $z$ axis.
$30.4 \mathrm{sec}$ and "low" forward velocity from 31.7 to $59.5 \mathrm{sec}$. Using driving time, forward velocities of each test were calculated. The result of calculation $\mathrm{X}_{\mathrm{MF}}$ with other constants is shown Table 5.

According to calculation, higher IA and lower forward velocity make $\mathrm{X}_{\mathrm{MF}}$ be lower. Similar result about tiller blades was already mentioned by Asl and Singh (2009).

\section{Relations of $\mathrm{X}_{\mathrm{MF}}$ and $\boldsymbol{a}_{\mathrm{hv}}$}

According to T-test with $10 \sim 90$ percentile of each data, $P G$ and NG had a significant difference $(p<0.05)$. This means the sign of $\mathrm{X}_{\mathrm{MF}}$ can assume unnecessary soil reaction occurs or not.

The group mean total exposure duration of PG was

Table 5. Result of calculation $X_{M F}$ with six factors in order installation angle

\begin{tabular}{|c|c|c|}
\hline $\begin{array}{c}\text { Installation angle } \\
\left(\left(^{\circ}\right)\right.\end{array}$ & $\begin{array}{l}\text { Forward velocity } \\
\qquad\left(\mathrm{mm} \mathrm{s}^{-1}\right)\end{array}$ & $\begin{array}{l}X_{M F} \\
(\mathrm{~mm})\end{array}$ \\
\hline 0 & 328.95 & -1.5948 \\
\hline 0 & 300.00 & -1.5369 \\
\hline 0 & 321.89 & -1.5807 \\
\hline 0 & 493.42 & -1.9239 \\
\hline 0 & 515.46 & -1.9679 \\
\hline 0 & 568.18 & -2.0734 \\
\hline 0 & 669.64 & -2.2764 \\
\hline 0 & 753.77 & -2.4448 \\
\hline 0 & 742.57 & -2.4223 \\
\hline 4 & 375.94 & 0.0745 \\
\hline 4 & 351.29 & 0.1336 \\
\hline 4 & 473.19 & -0.1586 \\
\hline 4 & 597.61 & -0.4568 \\
\hline 4 & 614.75 & -0.4979 \\
\hline 4 & 600 & -0.4625 \\
\hline 4 & 847.46 & -1.0557 \\
\hline 4 & 842.7 & -1.0443 \\
\hline 4 & 802.14 & -0.9470 \\
\hline 8 & 252.1 & 2.2454 \\
\hline 8 & 297.62 & 2.1180 \\
\hline 8 & 295.28 & 2.1246 \\
\hline 8 & 543.48 & 1.4298 \\
\hline 8 & 559.7 & 1.3844 \\
\hline 8 & 583.66 & 1.3174 \\
\hline 8 & 857.14 & 0.5519 \\
\hline 8 & 887.57 & 0.4667 \\
\hline 8 & 931.68 & 0.3432 \\
\hline
\end{tabular}




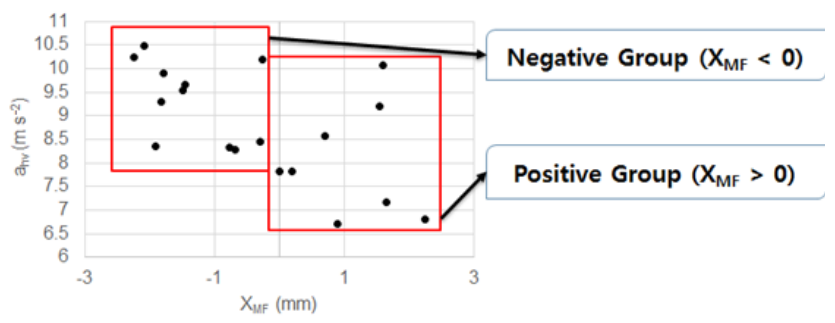

Figure 11. Result of $X_{M F}$ and $a_{h v}$.

Table 6. The group mean total (lifetime) exposure duration depended on $X_{M F}$ and daily using time (negative group: $X_{M F}<$ 0 , positive group: $X_{M F}>0$ )

\begin{tabular}{|ccc|}
$\begin{array}{c}\text { Daily using time } \\
\text { (hour) }\end{array}$ & $\begin{array}{c}\text { Negative group } \\
\text { (year) }\end{array}$ & $\begin{array}{c}\text { Positive group } \\
\text { (year) }\end{array}$ \\
\hline 1 & 8.96 & 10.5 \\
\hline 2 & 6.21 & 7.3 \\
\hline 3 & 5.01 & 5.89 \\
\hline 4 & 4.3 & 5.05 \\
\hline 5 & 3.82 & 4.49 \\
\hline 6 & 3.47 & 4.08 \\
\hline 7 & 3.2 & 3.76 \\
\hline 8 & 2.98 & 3.5 \\
\hline
\end{tabular}

improved by $17.53 \%$ compared with NG (Table 6). Therefore, proper IA can reduce hand-arm vibration effectively.

\section{Suggestion of minimum IA}

According to MAFRA (2002), when cutting angles are $30^{\circ}$ and $42^{\circ}$, power consumptions are $160 \sim 180 \%$ and about $200 \%$ compared with cutting angle is $17^{\circ}$, respectively. Cutting angle and IA are different (Figure 12), however two angle sizes have regular intervals. Therefore, bigger IA makes higher power consumption.

In this study, some minimum IAs were suggested in various conditions. The variables were disk radius, forward velocity and disk angular velocity (Table 7). The other values were fixed, weeding depth was $30 \mathrm{~mm}$, interval with $\mathrm{F}$ and $\mathrm{M}$ was $10 \mathrm{~mm}$.

According to Figure 13, minimum IAs of blade were 4 $27^{\circ}, 3 \sim 15^{\circ}$ and $2 \sim 10^{\circ}$ when disk radius were $100 \mathrm{~mm}$, $150 \mathrm{~mm}$ and $200 \mathrm{~mm}$, respectively. Minimum IA was bigger when the disk radius was smaller, disk angular velocity was smaller and translational velocity was bigger. Therefore, disk radius could be set big on permissible levels for reducing hand-arm vibration and power consumption. Also, high disk angular velocity enables to have high

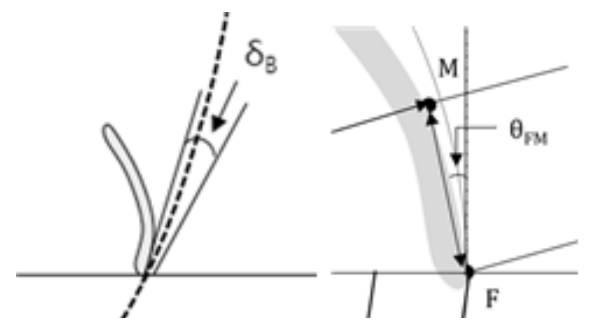

Figure 12. Cutting angle on left (MAFRA, 2002) and installation angle on right.

Table 7. Simulation variables and their values for determination of the minimum installation angle of blade

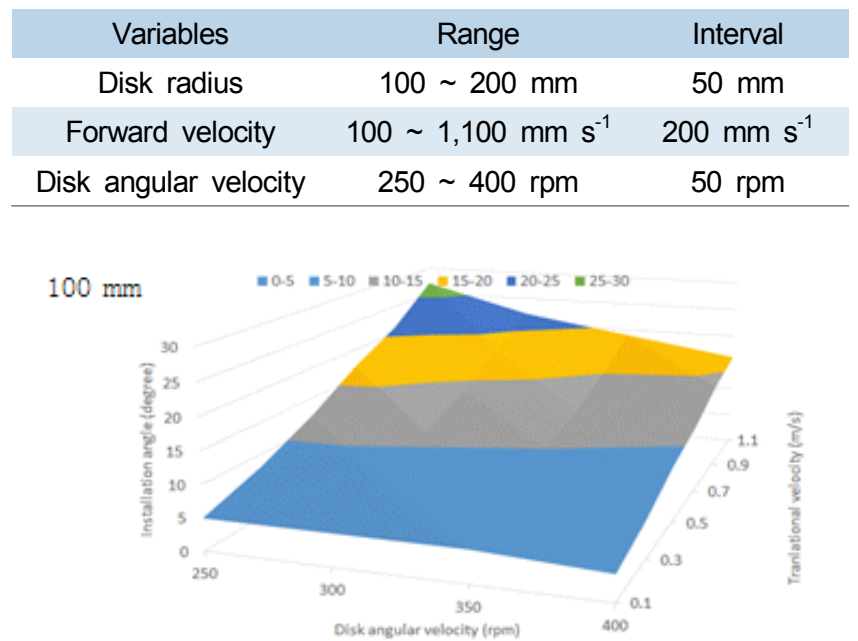

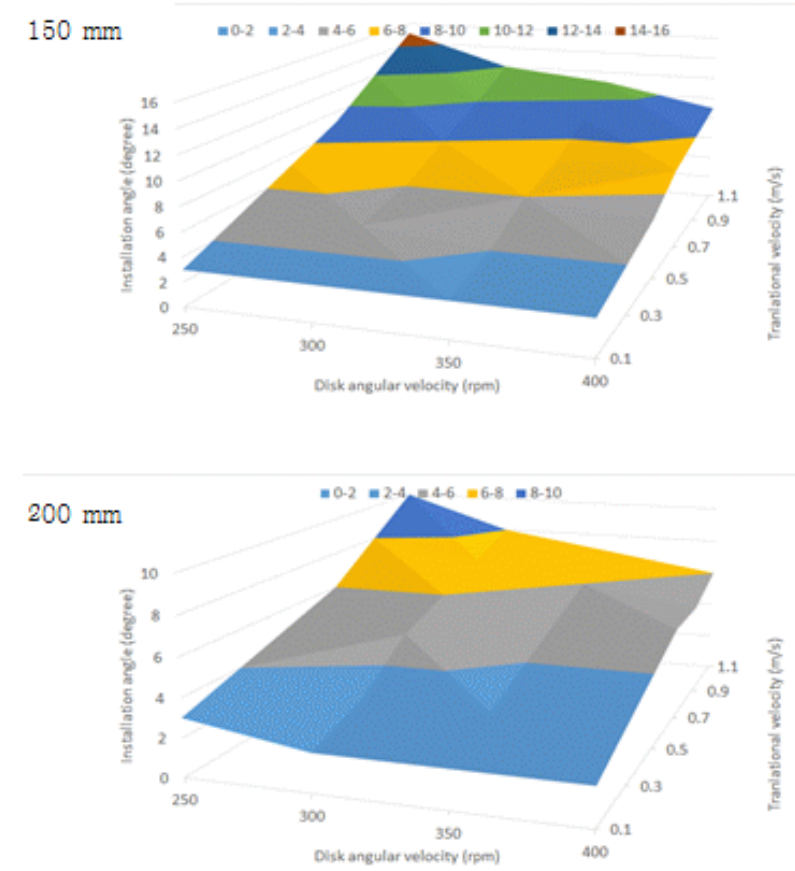

Figure 13. Recommended installation angle of weeding blade, according to disk angular velocity, translational velocity (up) and disk radius. 


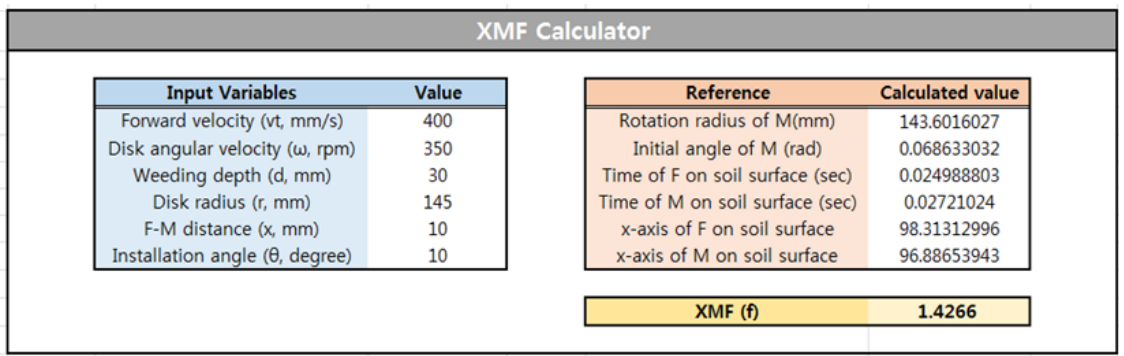

Figure 14. Calculator spread sheet (Excel 2013) for determination of the minimum installation angle.

translational velocity for smaller IA.

The $\mathrm{X}_{\mathrm{MF}}$ could be calculated by ' $\mathrm{X}_{\mathrm{MF}}$ calculator program' made by Excel 2013 (Microsoft, USA) (Figure 14). The program was based on design factor theory of weeding blade in this study.

\section{Conclusions}

The design factor theory of weeding blade for upward soil reaction reduction was derived. The trace interval of edge point and the other point on a weeding blade, $\mathrm{X}_{\mathrm{MF}}$ is the index for occurring unnecessary upward soil reaction. Evaluation of the theory was conducted based on ISO 5349:1. According to theoretical hypothesis and vibration measurement experiment, when $\mathrm{X}_{\mathrm{MF}}$ is bigger than 0 , hand-arm vibration will be reduced. $X_{\mathrm{MF}}$ can be increased by increasing installation angle. However, bigger installation angle produced higher power consumption. Therefore minimum installation angle is needed. In this study, some minimum installation angles were found out from theoretical equations in various conditions. Minimum installation angle was smaller, when disk angular velocity was faster and forward velocity was slower. Minimum installation angle was $4 \sim 27^{\circ}, 3 \sim 15^{\circ}, 2 \sim 10^{\circ}$ when disk radius were $100 \mathrm{~mm}, 150 \mathrm{~mm}$ and $200 \mathrm{~mm}$, respectively. Therefore, bigger disk and faster disk angular velocity have advantages about reduction hand-arm vibration and power consumption. $\mathrm{X}_{\mathrm{MF}}$ can be calculated easily from the $\mathrm{X}_{\mathrm{MF}}$ calculator spread sheet that was made by this study.

\section{Conflict of Interest}

The authors have no conflicting financial or other interests

\section{Acknowledgement}

This study was supported by "Cooperative Research Program for Agriculture Science \& Technology Development (Project No. PJ008257)" Rural Development Administration, Republic of Korea. Also, the authors would like to thank Tae-Ik Moon who is CEO of 'Tae-woong Agricultural Machinery' for his cooperation in this study.

\section{References}

Asl, J. H and S. Singh. 2009. Optimization and evaluation of rotary tiller blades: Computer solution of mathematical relations. Soil \& Tillage Research 106(2009):1-7.

Benny, J. M and D. C. P. Khoo. 1970. Preliminary Investigations into the Performance of Different Shaped Blades for the Rotary Tillage of Wet Rice Soil. J. agric. Engng Res. 15(1):27-33.

Dytran. 2013. Dytran Iinstruments Incorporated. Available at: www.dytran.com.

ISO. 2001. Mechanical vibration-Measurement and evaluation of human exposure to hand-transmitted vibration. ISO 5349-1:2001(E).

Jeong, H. K and J. K. Jang. 2012. Analysis of consumption of homemade organically processed food. Korean journal of organic agriculture 20(1):1-19 (In Korean, with English abstract).

Kim, C. K., H. K. Jeong and D. H. Moon. 2012. Production actual condition and market outlook of internal and external environmental friendly agricultural product. Agricultural Focus of Korea Rural Economic Institute Vol. 14 (In Korean).

Kim, K. B., E. K. Chung, K. H. You and J. K. Jang. 2012. Assessment on the actual vibration exposure of workers engaging in vibration induced works. Transactions of the KSNVE, 22(10):940-948 (In Korean, with English 
abstract).

Kim, S. S and N. W. Paik. 1996. Assessment of vibration produced by pneumatic hand tools used in automobile assembly. Korean Ind. Hyg. Assoc. J. 6(1):1-16 (In Korean, with English abstract).

KOSHA. 2012. A guideline for measurement and evaluation of part vibration. KOSHA GUIDE: H-77-2012 (In Korean).

MAFRA. 2002. Development of tractor rotary blade for energy saving. Final Research Report. Ministry of Agriculture, Food and Rural Affairs (In Korean).

NI. 2013. National Instruments Corporation. Available at: korea.ni.com.

Noh, K. K and P. Park. 2009. A study on measurement and assessment of local vibration by walking-type cultivator. Journal of Korea Safety Management \& Science 11(1):67-73 (In Korean, with English abstract).

Park, H. S and S. M. Huh. 2004. A study on measurement and analysis of local vibration induced by the powered hand tools used in automobile assembly lines. IE Interfaces 17(3):375-383 (In Korean, with English abstract).

Park, Y. J and K. U. Kim. 2002. Analysis and isolation of waling-type cultivator vibration transmitted to operator's hands. Journal of Biosystems Engineering 27(4): 273-283 (In Korean, with English abstract).

Park, Y. J., Y. S. Lee and K. U. Kim. 2004. Vibration reduction of walking-type cultivator's handle using modal analysis and operational defection shapes techniques. Journal of Biosystems Engineering 29(2): 101-108 (In Korean, with English abstract).

R Core Team . 2013. R: A language and environment for statistical computing. R Foundation for Statistical Computing, Vienna, Austria. Available at: www.Rproject.org.

Yim, S. H., H. S. Park and J. I. Yang. 2002. A study on the assessment of vibration produced by the powered hand tools used and hand-arm vibration syndrome prevalent in the shipbuilding industry. Journal of the Ergonomics Society of Korea 21(4):25-45 (In Korean, with English abstract).

Yoo, D. K. 2011. A study on strategy development for stabilization of developing new markets for organic products. Journal of Research Institute of Social Science 18(1):5-39 (In Korean, with English abstract). 